published within the last ten years on the anatomy and physiology of the hoof, methods of shoeing, and diseases of the horse's foot. It contains, as might be expected, an immense amount of valuable information on these subjects. Of special interest are the references to such important diseases of the foot as canker, side bone, sand-crack, navicular disease, and quittor, inasmuch as they embody descriptions of many modes of treatment that have never been published in English veterinary literature. We can cordially recommend the book to those who are desirous of putting themselves au courant in such matters.

Meat Inspection. By Thomas Walley, M.R.C.V.S., Principal of the Royal Veterinary College, Edinburgh. Scott \& Ferguson and Burness \& Co., Edinburgh.

ONE of the greatest blanks in English veterinary literature hitherto has been the lack of a book dealing with those diseases and conditions that render the flesh of the lower animals unsafe as an article of human food. The above work, of which we have seen some of the proof sheets, will fill up this lacuna. It will, we understand, be issued within a few days, and a more detailed notice of its contents will be given in our next number.

\title{
CLINICAL ARTICLES.
}

\section{MISCELLANEOUS CASES.}

By J. M'Fadyean, M.B., B.Sc., F.R.S.E., Royal Veterinary College, Edinburgh.

I INTEND to describe here a number of short but, I think, not uninteresting cases. Their description is placed in this section of the Journal merely as a matter of convenience, for, as will be observed, some of them have little claim to be ranged under the head of clinical articles, inasmuch as the facts that I am able to put on record regarding them are more of a pathological than of a clinical character.

\section{Echinococcus Cysts IN THE Liver of THE Horse.}

About twelve months ago I read in Professor Neumann's most excellent text-book-Traité des maladies parasitaires non microbiennes des animaux domestiques-the statement that the author knew only two recorded cases of echinococcus cysts in the liver of the horse. I was somewhat struck with the fact, for, although I had not kept any note of the cases, my memory informed me that I had on several occasions seen echinococcus cysts in the liver of dissecting-room subjects. Since that time I have therefore been careful to note all the cases that have come under my notice, and up to the present time these number three. 
Case I.-A portion of the liver in this case was sent to me in the month of February last, by Mr Spreull, F.R.C.V.S., Dundee. That gentleman, in making the autopsy of a horse, noticed in the uncut liver a number of what he at first thought might be tubercular nodules. On cutting into one or two of them, however, he found that they had liquid contents, and a piece of the liver containing several of the cysts was forwarded to me for examination. The cysts were of small size, the largest having a volume about equal to that of a walnut. Microscopic examination showed an immense number of young tæniæ floating in the liquid of the cysts.

Case II. - In the month of March last my attention was called to the liver of a dissecting-room pony. On examination $I$ found that it contained six small degenerated cysts. The capsule of each cyst was calcified, and the contents semi-solid. Microscopic examination of the latter revealed the presence of the characteristic hooklets of the young tæniæ.

Case III.-A large portion of this liver was brought to me from a knacker's a few weeks ago by my colleague Professor Baird. It contained an immense number of very perfect echinococcus cysts, varying in size from a walnut to a hazel nut. In a few the cyst wall was partly calcified, and in all the outer fibrous layer of the cyst wall was very thick. Attached to the inner or germinal layer of the wall of each hydatid there were innumerable minute yellowish granules, and microscopic examination showed that these were proligerous cysts, each containing an immense number of young tape-worm heads.

\section{A Case of Acute Endocarditis in a Bullock.}

The heart of this animal was sent to me in May last by $\mathrm{Mr}$ J. A. Thompson, M.R.C.V.S., Lurgan. It is an exquisite example of verrucose endocarditis affecting the mitral valve. Both cusps are almost entirely covered on their auricular surfaces with soft dirtywhite cauliflower-like excrescences, in consequence of which the auriculo-ventricular orifice is greatly reduced in size. The ventricular aspect of the cusps and the endocardium of the ventricle appear healthy. Two small vegetations are present on the aortic valve. The right side of the heart is unaffected.

The clinical history of the case, as supplied by Mr Thompson, was as follows:- The animal was about nine months old, and until within a few days of its death it appeared to be perfectly healthy. The first symptoms noted by the owner or attendant were dulness and the presence of a dropsical swelling in the intermaxillary space. Some laxative medicine was administered, and $\mathrm{Mr}$ Thompson was called in two days later. The animal was then found recumbent; it moaned, and had a very anxious expression. In addition to the dropsy of the intermaxillary space, $\mathrm{Mr}$ Thompson detected slight cedema of the dew-lap and a certain amount of ascites. There was no dropsy of the extremities. The pulse was frequent and irregular, and the first sound of the heart was inaudible. Both jugulars were greatly distended, and venous pulse was very notable in them. The visible mucous membranes appeared quite bloodless, but this may have been partly ascribable to the fact that several pints of blood had been abstracted before $\mathrm{Mr}$ Thompson was called in. There was well- 
marked twitching of the muscles in the region of the shoulders. The animal died on the following day.

A remarkable and as yet unexplained point in comparative pathology is that, while in the human subject the mitral valve is far more frequently the seat of disease than the tricuspid, the opposite appears to be the case in the lower animals, and especially in cattle. Thus, in nine cases of endocarditis observed by Meyer, the tricuspid was affected eight times, and the mitral only four times. As already stated the valves of the right side were unaffected in Mr Thompson's case, and the jugular pulse noted during life must be set down to over-distension of the right ventricle, and consequent insufficiency of the tricuspid valves.

\section{Extensive Tubercular Disease of the Wall of The HEART IN A COW.}

The following case is of interest on account of the comparative rarity of tubercular disease of the myocardium, and as illustrating what extensive lesions of the heart wall are compatible with life.

Early in November last I received from Mr J. Burnett, F.R.C.V.S., Maybole, the heart of a cow showing the following lesions:-There was extensive tubercular disease of the pericardium, in consequence of which the serous sac was almost entirely obliterated. From the visceral layer of the membrane the tubercular process had invaded the muscular tissue of the heart. Almost the entire wall of both ventricles was more or less affected, and over considerable areas the process had almost reached the endocardium. In these areas the advancing tubercular infiltration appeared to the naked-eye to have led to total destruction of the muscular tissue. Where the disease was most extensive there was pronounced caseation and a considerable amount of calcification. The endocardium was healthy, but on laying open the roots of the pulmonary artery and aorta the lining membrane of these vessels was seen to be studded with small flat warty growths.

$\mathrm{Mr}$ Burnett has supplied me with the following history of the cow :He was first asked to see the animal about the beginning of August last. At that time the pulse was 112 per minute and very feeble. The cow took her food well, but steadily lost condition. Heart affection was diagnosed, and the progressive emaciation suggested tuberculosis. As no improvement resulted from treatment, at the end of two months, at Mr Burnett's suggestion, the cow was killed. At the autopsy there were found, besides the above-described cardiac disease, the well-known perlsucht lesions of the peritoneum and pleura, and tubercular nodules in the liver. The lung substance was free from tubercular disease.

\section{TUBERCULOSIS OF THE HORSE.}

On several previous occasions I have called the attention of readers of the Journal to the fact that the horse has no such immunity from tuberculosis as he has been credited with by veterinary authors in this country, and that many cases of so-called lymphadenoma of the horse's spleen are in reality instances of equine tuberculosis. The traditional doctrine that the horse is never the subject of this disease is, I believe, 
still taught in one veterinary school, and that opinion may be indefinitely entertained as long as it is considered that a naked-eye inspection is adequate to determine whether a given lesion is tubercular or not. The following case ought to give pause to those who, without ever having had recourse to microscopic examination and staining for the specific bacillus, are ready to declare that none of the cases of so-called lymphadenoma that have come under their observation were examples of tuberculosis.

On the 14th of the current month (December) a knacker brought to me a portion of a horse's spleen, with the report that it had been taken from a horse that had been under treatment by $\mathrm{Mr}$ Rutherford, F.R.C.V.S., Edinburgh. It contained a number of what, on casual inspection, appeared to be large tumours. These gave to the surface of the organ an irregularly bosselated or humpy character. The largest was about as big as a cocoa-nut, and for the most part they had a firm fibrous consistence. On cutting into these tumours they were found to be rather ill-defined, shading gradually into the remnant of the splenic tissue. At some parts they appeared to be largely composed of dense fibrous tissue, suggesting almost a scirrhous carcinoma; at other points their texture was more of a sarcomatous character. In all the larger growths there was caseation, the caseous material being of a very firm character. Over large areas, however, the caseation was very slight, and there was very little calcification.

Suspecting that these lesions were of a tubercular nature, I immediately stained, in the usual way, a scraping from the cut surface of one of the tumours, and was not surprised to find that it contained great numbers of tubercle bacilli. As is commonly the case in these tumour-like tubercular growths of the horse, the bacilli are very numerously present, and they are grouped together, even in coverglass preparations, in large sheaves and rounded clusters.

Part of this same spleen, I may add, was brought by Mr Rutherford to the examination hall, for use as a specimen in the examination of students at a diet of the Board of Examiners of the Royal College of Veterinary Surgeons, but the tubercular nature of the tumours had not then been recognised. In saying this, I do not in the least intend to cast any reflection upon Mr Rutherford. At the present time probably most practitioners, following the example of some of our text-books, would have described the splenic growths as lymphadenomatous tumours, and no one would have been justified in pronouncing them to be tubercular from their macroscopic characters alone. But it is equally true that, in view of the previously published cases, the naked eye characters of the lesions suggested the possibility of their being tubercular; and certainly, without having had recourse to a search for Koch's bacillus, no one would have been justified in declaring that the case was not one of tuberculosis. In short, the actual nature of tumour-like growths in the spleen and lymphatic glands of the horse must remain a matter of speculation in every case in which a search for the tubercle bacillus has not been made.

\section{Two Cases of Discomycosis Equi.}

Case 1.-In last issue of the Journal I placed on record a case of mycotic funiculitis-that is to say, a case of so-called "scirrhous 
cord," in which there was present the micro-parasite termed the discomyces. The excised tumour had been sent to me by Mr Malcolm, F.R.C.V.S., Birmingham, and the appeal made at the end of my note on that case brought me a short time afterwards a second specimen of the same kind. This latter tumour was sent by Mr Mahony, Veterinary Surgeon, Maryborough, who had removed it from a five-year-old gelding. In all respects this scirrhous cord was identical with that described in the September number of the Journal. It was composed in the main of dense white fibrous tissue, but on section it showed a number of soft centres. These were in reality sections of small cavities and sinuses containing material which might have been described as pus, but which had a peculiar mucoid character and a brownish colour. A cover-glass preparation of this material showed numerous colonies of the discomyces, or micrococcus ascoformans.

Case II.-A short time ago I was requested by Professor Walley to make a microscopic examination of the thigh of a mare which had been sent to the College by $\mathrm{Mr}$ Robson, Veterinary Surgeon, Penrith. The lesions presented by the limb were of a most formidable character. The inner muscles of the thigh and upper part of the leg appeared to have been invaded by new tissue, which at some plices was dense and fibrous, and at others more sarcomatous in texture. This new tissue did not form at any place circumscribed tumours. It had rather the character of a very irregularly distributed inflammation of the muscular tissue, which had led to the substitution of cicatricial fibrous tissue for the normal muscle elements. On cutting into the muscular mass of the limb, all stages in the process could be followed with the naked eye, from the apparently normal muscle to parts composed entirely of fibrous tissue. But what struck me sooner than the distribution of the new tissue was the fact that it everywhere presented small cavities and sinuses containing material apparently identical with what I had previously seen in the scirrhous cords sent by $\mathrm{Mr}$ Malcolm and $\mathrm{Mr}$ Mahony. On scrutinising with the naked eye a little of this material smeared on the blade of the knife, there were clearly visible numerous little opaque whitish granules. The experience gained from previous cases immediately suggested that these were colonies of the discomyces, and a microscopic examination of an unstained cover-glass preparation confirmed this diagnosis beyond any doubt. From the extensive lesions present in the limb I obtained an abundant material suitable for studying the characters of the parasite and the structural alterations which it excites when invading the muscles. My observations on these heads I hope to give in an early number of the Journal.

The clinical history of this case is briefly as follows:- The mare at the time when she was killed was about fourteen years of age, and she had been under observation for the disease of the leg for over three years. When $\mathrm{Mr}$ Robson was first called in he found a tumour inside the thigh, close to the mammary gland. On opening this swelling there issued from it what Mr Robson describes as "a gluey substance, having a colour like coffee." The opening soon granulated and cicatrised, but a discharge broke out at fresh places, and this went on until the animal was destroyed.

The discomyces equi excites lesions which bear a close resemblance to those set up by the actinomyces, but in the case of the former the 
march of the disease appears to be generally less rapid and the lesions are more benign, in the sense that they may for a long time be localised to the point of entrance of the virus. The tendency to metastasis appears to be very slight in the case of the discomyces, as is illustrated by the not infrequent persistence of scirrhous cords for years, without the formation of any secondary tumours. But when once the parasite gains entrance to the muscular or intermuscular tissue, as in Mr Robson's case, its effects may be much more widespread and destructive than they generally are in the stump of the spermatic cord.

\section{A CASE OF TOTAL NECROSIS OF THE SCAPULA OF A HORSE,}

By F. Barling, M.R.C.V.S., Ross, Herefordshire.

THE subject of this note was a five-year-old bay mare pony, the property of $\mathrm{Mr} \mathrm{H}$ 8th September 1888. It was then lame on the shoulder, which was much swollen, and there was a small wound leading down to the spine of the scapula. I ordered hot fomentations to be applied to the part, but at the end of five or six days the mare was brought back in much the same condition as before. At this time I examined the shoulder carefully, but could not detect any fracture. After walking for a few yards the pony went nearly sound. I had her placed in a loose box and kept quiet, and on the 2oth September I was sent for, as the lameness had become much more severe. I found her quite unable to move the limb, and the scapular region was greatly swollen. Having administered a doze of physic, I prescribed continuous hot fomentations to be applied to the swollen and painful part. The wound at this time was discharging, and I had this dressed morning and evening with an antiseptic lotion. I informed the owner that I suspected there had been a fracture, but from the great swelling I was unable to detect it.

The condition of matters continued to be much the same for a week, at the end of which time I enlarged the wound, and explored the parts with my finger, but without discovering any fracture. The same treatment was continued, and ten days later the swelling had become much reduced, and the wound had healed, but there was no improvement in the lameness. I now applied a blister over the region of the scapula, and repeated it ten days afterivards. Subsequently there was some diminution of the lameness, and three weeks later the pony was able to walk about a mile to the homestead of the owner.

A short time afterwards, on visiting the patient, I found that a swelling had formed over the upper and posterior part of the scapula. The part was fomented for a week, and I then lanced the abscess which had meanwhile formed, and after that had been evacuated I could detect a fracture detaching a portion of the scapula including the dorsal angle.

Feeling certain that there was no hope of the fracture uniting, I proposed to chloroform the animal, and remove the detached portion of bone, but to this the owner would not consent. I kept the case under observation for about a month afterwards, and then informed 